\title{
Enantioselective Access to Dialkyl Amines and Alcohols via Ni-Catalyzed Reductive Hydroalkylations
}

\section{Shan Wang}

Southern University of Science and Technology

Tian-Yi Zhang

Southern University of Science and Technology

Jian-Xin Zhang

Southern University of Science and Technology

Huan Meng

Southern University of Science and Technology

\section{Bi-Hong Chen}

Southern University of Science and Technology

Wei Shu ( $\square$ shuw@sustech.edu.cn )

Southern University of Science and Technology https://orcid.org/0000-0003-0890-2634

\section{Article}

Keywords: Spatial and Electronic Similarity, Enantioenrichment, Functional Group Tolerance

Posted Date: January 18th, 2021

DOI: https://doi.org/10.21203/rs.3.rs-128934/v1

License: (c) (1) This work is licensed under a Creative Commons Attribution 4.0 International License. Read Full License

Version of Record: A version of this preprint was published at Nature Communications on May 13th, 2021. See the published version at https://doi.org/10.1038/s41467-021-22983-7. 


\section{Abstract}

Chiral dialkyl amines and alcohols are ubiquitous in pharmaceuticals, pesticides, natural products and fine chemicals, yet difficult to access due to the challenge to differentiate between the spatially and electronically similar alkyl groups. Herein, we report a nickel-catalyzed enantioselective reductive hydroalkylation of acyl enamines and enol esters with alkyl halides to afford enantioenriched a-branched aliphatic amines and alcohols in good yields with excellent levels of enantioselectivity. The operationally simple protocol provides a straightforward access to chiral dialkyl amine and alcohol derivatives from simple starting materials with great functional group tolerance.

\section{Full Text}

Chiral aliphatic amines and alcohols are widespread substructures in pharmaceutical molecules, natural products and organic materials, and serve as common chiral building blocks for other functional groups and value-added molecules synthesis. ${ }^{1-3}$ Additionally, over half of small molecule drugs are the derivatives of chiral aliphatic amines and alcohols among the top 200 best-selling drugs (Scheme 1a). ${ }^{4}$ Thus, the enantioselective synthesis of pure aliphatic amines and alcohols has been recognized as a long-term interest in chemistry community. Over the past decades, significant progress has been made in this field enabled by enantioselective $\mathrm{C}-\mathrm{H}$ amination/oxygenation, ${ }^{5-8}$ addition of alkyl organometallic reagents to imines or aldehydes, ${ }^{9-13}$ hydrogenation of imines, enamines, ketones, or enol esters. ${ }^{14-19}$ However, chiral catalysts have difficulty in identifying different faces of prochiral centers bearing two alkyl groups with similar steric and electronic properties. ${ }^{20}$ Thus, these methods are typically applied to build chiral aliphatic amines and alcohols with the stereogenic center adjacent to aryl or carbonyl groups (Scheme 1b). ${ }^{14,21-24}$ To control the stereoselectivity of asymmetric reactions for regular dialkyl amines or alcohols still remains challenging. In 2020, Zhou group reported a breakthrough in Ir-catalyzed asymmetric hydrogenation of dialkyl ketones to afford chiral aliphatic alcohols with good enantioselectivity enabled by a rationally designed bulky phosphine ligand. ${ }^{25}$ Buchwald developed a seminal work on $\mathrm{Cu}-\mathrm{H}$ catalyzed hydroamination of internal alkenes to achieve chiral dialkyl amines. ${ }^{26,27}$ In 2016, Fu group reported a pioneer work on $\mathrm{Ni}-\mathrm{H}$ catalyzed racemic reductive hydrofunctionalizations of alkenes with aryl or alkyl halides, ${ }^{28}$ which have become a promising alternative for traditional asymmetric $\mathrm{C}-\mathrm{C}$ cross-coupling reaction to construct saturated stereogenic carbon centers. ${ }^{28-38}$ The use of readily available and bench-stable alkenes as a masked nucleophile in the presence of silane circumvents the use of stoichiometric and often sensitive organometallic reagents, which usually require time-consuming preformation. ${ }^{39,40}$ The abundance of alkene as well as the mild conditions significantly enhanced the scope and functional group tolerance of this reductive cross-coupling strategy. Fu group reported the seminal work on the reductive anti-Markovnikov hydroalkylation of alkenes with activated secondary alkyl halides to build a stereogenic center original from alkyl halides. ${ }^{41-44}$ The use of unactivated alkyl halides to build stereogenic center original from alkenes remains elusive due to the reversible $\mathrm{Ni}-\mathrm{H}$ insertion onto alkenes and the propensity of chain-walking. ${ }^{45,46}$ Recently, our group developed the Ni-H 
catalyzed reductive hydroalkylation of acrylates via anti-Markovnikov hydrometalation, giving the enantioenriched tertiary amides by forging a stereogenic center original from acrylates. ${ }^{47}$ In 2020 , Hu group reported a reductive hydroalkylation of vinyl boronates to give chiral secondary alkyl boronates enabled by the anchoring effect of boron. ${ }^{48}$ As part of our continuous interest in the enantioselective reductive hydrofunctionalizations of alkenes, we envisioned the use of alkene adjacent to nitrogen or oxygen to undergo enantioselective reductive hydroalkylation would furnish enantioenriched secondary aliphatic amine and alcohol derivatives (Scheme 1c). Herein, we reported the $\mathrm{Ni}-\mathrm{H}$ catalyzed regio- and enantioselective reductive hydroalkylation of acyl enamines and enol esters with alkyl iodides to forge a stereogenic carbon center next to nitrogen or oxygen original from alkenes in high enantioselectivity, providing a unified protocol for rapid access to chiral dialkyl amine and alcohol derivatives which are difficult to access otherwise. ${ }^{49-51}$

To test the feasibility of the reaction, we set out to identify the reaction parameters using acyl enamine 1a with 1-iodo-3-phenylpropane $\mathbf{2 a}$ as substrate in the presence of silane. (Table 1 and Tables S1-13) ${ }^{52}$ First, a wide range of chiral ligands were tested for this reaction using $\mathrm{NiBr}_{2}$ glyme (10 mol\%) as the nickel catalyst precursor, trimethoxysilane (TMS) as hydride source, and potassium phosphate monohydrate as base in diethyl ether at room temperature (Table 1, entries 1-9 and Table S1). When pyridine-oxazolidine ligand (L1 or L2) was used, the desired reductive hydroalkylation product $\mathbf{3 a}$ was obtained in $54 \%$ and $29 \%$ yields with low enantiomeric excesses ( $2 \%$ and $15 \%$ ), respectively (Table 1, entries 1 and 2). Ph-Box ligands (L3-L6) could catalyze the reaction, giving 3a in low yields with low enantioselectivities (Table 1, entries 3-5). Increasing the steric hindrance at a-position to oxygen increased the enantioselectivity of 3a to $50 \%$ ee (Table 1, entries 6 and 7). Modifying the methyl group on L4 to bulkier groups significantly improved the enantioselectivity of $\mathbf{3 a}$ (Table 1, entries 8-10). The use of $\mathbf{L} \mathbf{9}$ delivered $\mathbf{3 a}$ in $20 \%$ yield with $90 \%$ ee. Using DEMS as hydride source slightly increased the enantioselectivity of $3 \mathbf{a}$ to $94 \%$ (Table 1 , entry 11). Next, the solvent for the reaction was evaluated. The use of DMA or DMF dramatically increased the efficiency of the reaction, delivering $3 a$ in up to $99 \%$ yield with diminished enantiomeric excess (Table 1, entries 12 and 13). The mixing of ether with DMA or DMF could increase the enantioselectivity of $\mathbf{3 a}$ without erasing the efficiency of the reaction (Table 1, entries 14 and 15). Further optimization of the nickel precursor and reaction temperature improved the yield and enantioselectivity of 3a (Table 1, entries 16-18). The use of Ni(COD) 2 (10 mol\%), L9 (12 mol\%), DMMS (3 equiv) in $\mathrm{Et}_{2} \mathrm{O}$ and DMF (3:1) gave $3 a$ in $93 \%$ yield with $92 \%$ ee (Table 1 , entry 19$)$.

With the optimized conditions in hand, we turned to evaluate the scope of this reaction. First, we tested different alkyl iodides with tertiary acyl enamine 1a (Fig. 1). 4-Phenylbutyliodide was converted to chiral amide 3 b in $93 \%$ yield with $92 \%$ ee. 2-Phenyl-1-iodoethane and a-branched alkyl iodides could be transformed into corresponding amine derivatives (3c and $\mathbf{3 d}$ ) in $87 \%$ and $58 \%$ yields with $89 \%$ ee. Heterocycles, such as carbazoles, indoles, and thiophenes, worked well in the reaction, furnishing the regio- and enantioselective hydroalkylation products $(\mathbf{3 e}-3 \mathbf{g})$ in $64-94 \%$ yields with $91 \%$ ee. Other functional groups, such as amides, esters, ethers were also compatible under the reaction conditions, delivering the desired chiral amine derivatives (3h-3k) in 56-83\% yields with $89 \%-92 \%$ ee. Moreover, 
silylethers and arylchlorides were tolerated in the reaction, giving the desired products ( $\mathbf{3 l}$ and $\mathbf{3 m}$ ) in $85 \%$ and $95 \%$ yields with $74 \%$ and $88 \%$ ee, leaving chemical handles for further elaboration. Internal acyl enamine reacted to give corresponding dialkyl amide $\mathbf{3 n}$ in moderate yield with $93 \%$ ee.

Next, the scope of acyl enamines was tested (Fig. 2). A wide range of secondary acyl enamines were well tolerated in this reaction, forming a myriad of enantioenriched amides in good efficiency with excellent levels of enantioselectivity in the presence of L41. Various aromatic amides were good substrates for this reaction (4a-40). Electron-donating substituted aromatic acyl enamines could be converted to corresponding hydroalkylated products (4a-4f) in 68\%-90\% yields with $90 \%-95 \%$ ee. Electron-withdrawing substituents, such as trifluoromethyl, cyano, ester, fluoride, were well-tolerated under the reaction conditions, giving the desired products (4g-4j) in 74\%-89\% yields with $93 \%-96 \%$ ee. Fused aromatic and heteroaromatic acyl enamines, including naphthalene, furan, thiophene, and pyridine, were transformed into corresponding chiral amides (4k-40) in $49-88 \%$ yields with $89 \%-95 \%$ ee. The structure and absolute configuration of the product was determined by the X-ray diffraction analysis of 4 I. Aliphatic acyl

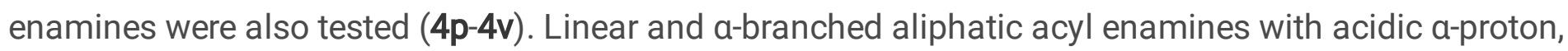
such as methyl, n-propyl, isopropyl, cyclopropyl, cyclohexyl, were all good substrates for this reductive hydroalkylation reaction, affording corresponding chiral amides (4p-4t) in 51-88\% yields with $90 \%-96 \%$ ee. a-Tertiary alkyl acyl enamines reacted to give $4 \mathbf{u}$ in $84 \%$ yield with $92 \%$ ee. $\mathrm{N}$-methyl aliphatic acyl enamine was converted to $\mathbf{4 v}$ in $79 \%$ yield with $80 \%$ ee.

Then the scope for alkyl iodide for secondary acyl enamines was examined (Fig. 3). Secondary acyl enamines gave better enantioselectivity using the analogue ligand L41. 5-(2-lodoethyl)-2,3dihydrobenzofuran was successfully hydroalkylated to give 5 a in $84 \%$ yield with $96 \%$ ee. The structure and absolute configuration of $\mathbf{5 a}$ was further determined by the X-ray diffraction analysis. It is noteworthy that the minimal structurally different dialkyl amine derivative $\mathbf{5 b}$ was obtained by this protocol in $65 \%$ yield with $94 \%$ ee. Other 1 -iodoalkanes were also successfully converted to corresponding amine derivatives (5c-5e) in 63-80\% yields with $93 \%-98 \%$ ee. Chiral aminoalcohol and aminoester derivatives (5f$5 \mathrm{~h}$ ) were obtained in $62-72 \%$ yields with $92 \%-94 \%$ ee. Cyclic secondary alkyl iodides were also reactive under the reaction conditions to furnish the desired products $\mathbf{5 i}$ and $\mathbf{5 j}$ in $66 \%$ and $61 \%$ yields with $98 \%$ and $92 \%$ ee. To demonstrate the robustness and usefulness of this protocol, we applied this reaction to late-stage functionalization of natural product derivatives. (+)-Borneol, L-menthol, cholesterol, and vitamin E derived acyl enamines could be transformed to give corresponding chiral amides (5k-5n) in $45 \%-87 \%$ yields with $97: 3$ to $98: 2 \mathrm{dr}$.

Next, enol esters were tested under the reaction conditions. To our delight, various enol esters could be tolerated and a wide range of dialkyl alcohol derivatives were obtained in high enantioselectivity, which are difficult to access otherwise (Fig. 4). Aromatic or aliphatic acid derived enol esters were all good substrates for this reaction, furnishing corresponding chiral esters (6a-6c) in $53 \%-73 \%$ yields with $80-92 \%$ ee. Alkyl iodides containing ester, ether, thiophene, amide could be transformed to corresponding chiral alcohol derivatives (6d-6g) in 51\%-80\% yields with $90 \%-95 \%$ ee. Notably, 1 -iodohexane and 1 -iodobutane were successfully involved in the reaction to give octan-2-ol (6h) and hexan-2-ol (6i) derivatives in 77\% 
and $54 \%$ yields with $90 \%$ and $96 \%$ ee, respectively. Secondary alkyl halides and internal enol esters were both compatible in the reaction, furnishing the desired products $(\mathbf{6 j}$ and $\mathbf{6 k})$ in synthetic useful yields with $97 \%$ ee. The absolute configuration of the chiral ester was confirmed to be $R$ by comparison to literature. ${ }^{53}$ Furthermore, literature procedures proved dialkyl free amines and alcohols could be obtained via hydrolysis without erosion of enantioselectivities, ${ }^{54,55}$ which further enhanced the synthetic utility of this method.

Then, we carried out the reaction using deuterated silane $\left(\mathrm{PhSiD}_{2}\right)^{32}$ under otherwise identical to standard conditions (eq. 1). Deuterated hydroalkylation product 4 a- $d$ was formed in $61 \%$ yield with $93 \%$ ee. Only one deuterium incorporation ( $>95 \% \mathrm{D}$ ) was exclusively delivered to $\beta$-position to nitrogen of amide $4 \mathrm{a}-d$. No deuterium incorporation was found at a-position to nitrogen of $4 \mathrm{a}-\mathrm{d}$. The result indicated that $\mathrm{Ni}-\mathrm{H}$ insertion onto acyl enamines to form alkyl-Ni species might be irreversible.

Based on the mechanistic results and literature, ${ }^{28-34,41-44,47,48}$ a tentative mechanism is proposed and depicted in Fig. 5. Nickel hydride species could be generated from ligated $\mathrm{Ni}(\mathrm{I})$ precursor in the presence of silane and base. $\mathrm{Ni}-\mathrm{H}$ would coordinate with acyl enamines or enol esters (1) to give M1, which could undergo regio- and enantioselective hydrometalation to generate alkyl nickel intermediate $\mathbf{M} 2$. M2 could oxidize alkyl halides (2) to form $\mathrm{Ni}(\mathrm{III})$ intermediate $\mathbf{M} 3$, which could undergo reductive elimination to give final amine or alcohol derivatives $\mathbf{3}$ and regenerate $\mathrm{Ni}(\mathrm{I})$ catalyst.

In summary, a unified protocol for Ni-catalyzed reductive hydroalkylation of acyl enamines and enol esters with alkyl iodides under mild conditions was developed for the first time. The use of chiral BOXbased ligand enables the direct access of chiral dialkyl amine and alcohol derivatives in good yields with excellent levels of enantioselectivity, providing a straightforward alternative to pure aliphatic amine and alcohol derivatives which are traditionally challenging to access.

\section{Declarations}

\section{Acknowledgements}

Financial support from NSFC (21971101 and 21801126), Guangdong Basic and Applied Basic Research Foundation (2019A1515011976), Thousand Talents Program for Young Scholars, The Pearl River Talent Recruitment Program (2019QN01Y261), and Guangdong Provincial Key Laboratory of Catalysis (No. 2020B121201002) is sincerely acknowledged. We acknowledge the assistance of SUSTech Core Research Facilities. We thank Dr. Xiaoyong Chang (SUSTech) for X-ray crystallographic analysis of $\mathbf{4 I}$ and 5 a.

\section{References}

1. Nugent, T. C. \& El-Shazly, M. Chiral Amine Synthesis-Recent Developments and Trends for Enamide Reduction, Reductive Amination, and Imine Reduction. Synth. Catal. 352, 753-819 (2010). 
2. Kittakoop, P., Mahidol, C. \& Ruchirawat, S. Alkaloids as Important Scaffolds in Therapeutic Drugs for the Treatments of Cancer, Tuberculosis, and Smoking Cessation. Top. Med. Chem. 14, 239-252 (2014).

3. Trowbridge, A., Walton, S. M. \& Gaunt, M. J. New Strategies for the Transition-Metal Catalyzed Synthesis of Aliphatic Amines. Chem. Rev. 120, 2613-2692 (2020).

4. McGrath, N. A., Brichacek, M. \& Njardarson, J. T. A Graphical Journey of Innovative Organic Architectures that Have Improved Our Lives. J. Chem. Educ. 87, 1348-1349 (2010).

5. Davies, H. M. L. \& J. R. Manning, Catalytic C-H Functionalization by Metal Carbenoid and Nitrenoid Insertion. Nature 451, 417-424 (2008).

6. Park, Y., Kim, Y. \& Chang, S. Transition Metal-Catalyzed C-H Amination: Scope, Mechanism, and Applications. Chem. Rev. 117, 9247-9301 (2017).

7. Jia, Z.-J., Gao, S. \& Arnold, F. H., Enzymatic Primary Amination of Benzylic and Allylic C(sp3)-H Bonds. J. Am. Chem. Soc. 142, 10279-10283 (2020).

8. Nakafuku, K. M., Zhang, X., Wappes, E. A., Stateman, L. M., Chen, A. D. \& Nagib, D. A. Enantioselective Radical C-H Amination for the Synthesis of $\beta$-Amino Alcohols. Nat. Chem. 12, 697-704 (2020).

9. Liu, G. C., Cogan, D. A. \& Ellman, J. A. Catalytic Asymmetric Synthesis of tert-Butanesulfinamide. Application to the Asymmetric Synthesis of Amines. J. Am. Chem. Soc. 119, 9913-9914 (1997).

10. Fujihara, H., Nagai, K. \& Tomioka, K. Copper-Amidophosphine Catalyst in Asymmetric Addition of Organozinc to Imines. J. Am. Chem. Soc. 122, 12055-12056 (2020).

11. Boezio, A. A. \& Charette, A. B. Catalytic Enantioselective Addition of Dialkylzinc to NDiphenylphosphinoylimines. A Practical Synthesis of a-Chiral Amines. J. Am. Chem. Soc. 125, 16921693 (2003).

12. Veguillas, M., Solà, R., Shaw, L. \& Maciá, B. Catalytic Asymmetric Addition of Organolithium Reagents to Aldehydes. Eur. J. Org. Chem. 1788-1794 (2016).

13. Fernández-Mateos, E., Maciá, B., Yus, M. Catalytic Enantioselective Addition of Alkyl Grignard Reagents to Aliphatic Aldehydes. Adv. Synth. Catal. 355, 1249-1254 (2013).

14. Friedfeld, M. R., Zhong, H., Ruck, R. T., Shevlin, M. \& Chirik, P. J. Cobalt-Catalyzed Asymmetric Hydrogenation of Enamides Enabled by Single-Electron Reduction. Science 360, 888-893 (2018).

15. Massaro, L., Zheng, J., Margarita, C. \& Andersson, P. G. Enantioconvergent and Enantiodivergent Catalytic Hydrogenation of Isomeric Olefins. Chem. Soc. Rev. 49, 2504-2522 (2020).

16. Jiang, Q., Jiang, Y., Xiao, D., Cao, P. \& Zhang, X. Highly Enantioselective Hydrogenation of Simple Ketones Catalyzed by a Rh-PennPhos Complex. Angew. Chem. Int. Ed. 137, 1100-1103 (1998).

17. Ohkuma, T., Sandoval, C. A., Srinivasan, R., Lin, Q., Wei, Y., Muñiz, K. \& Noyori, R. Asymmetric Hydrogenation of tert-Alkyl Ketones. J. Am. Chem. Soc. 127, 8288-8289 (2005).

18. Yamamura, T., Nakatsuka, H., Tanaka, S. \& Kitamura, M. Asymmetric Hydrogenation of tert-Alkyl Ketones: DMSO Effect in Unification of Stereoisomeric Ruthenium Complexes. Angew. Chem. Int. Ed. 52, 9313-9315 (2013). 
19. Garbe, M., Junge, K., Walker, S., Wei, Z., Jiao, H., Spannenberg, A., Bachmann, S., Scalone, M. \& Beller, M. Manganese(I)-Catalyzed Enantioselective Hydrogenation of Ketones Using a Defined Chiral PNP Pincer Ligand. Angew. Chem. Int. Ed. 56, 11237-11241 (2017).

20. Štefane, B. \& Požgan, F. Advances in Catalyst Systems for the Asymmetric Hydrogenation and Transfer Hydrogenation of Ketones. Catal. Rev. 56, 82-174 (2014).

21. Kobayashi, S., Mori, Y., Fossey, J. S. \& Salter, M. M. Catalytic Enantioselective Formation of C-C Bonds by Addition to Imines and Hydrazones: A Ten-Year Update. Chem. Rev. 111, 2626-2704 (2011).

22. Miyabe, H., Ushiro, C., Ueda, M., Yamakawa, K. \& Naito, T. Asymmetric Synthesis of a-Amino Acids Based on Carbon Radical Addition to Glyoxylic Oxime Ether. J. Org. Chem. 65, 176-185 (2000).

23. Friestad, G. K., Shen, Y. \& Ruggles, E. L. Enantioselective Radical Addition to N-Acyl Hydrazones Mediated by Chiral Lewis Acids. Angew. Chem. Int. Ed. 42, 5061-5063 (2003).

24. Cho, D. H. \& Jang, D. O. Enantioselective Radical Addition Reactions to the C-N Bond Utilizing Chiral Quaternary Ammonium Salts of Hypophosphorous Acid in Aqueous Media. Chem. Commun. 50455047 (2006).

25. Zhang, F.-H., Zhang, F.-J., Li, M.-L., Xie, J.-H. \& Zhou, Q.-L. Enantioselective Hydrogenation of Dialkyl Ketones. Nat. Catal. 3, 621-627 (2020).

26. Pirnot, M. T., Wang, Y.-M. \& Buchwald. S. L. Copper Hydride Catalyzed Hydroamination of Alkenes and Alkynes. Angew. Chem. Int. Ed. 55, 48-57 (2016).

27. Liu, R. Y. \& Buchwald, S. L. CuH-Catalyzed Olefin Functionalization: From Hydroamination to Carbonyl Addition. Acc. Chem. Res. 53, 1229-1243 (2020).

28. Lu, X., Xiao, B., Zhang, Z., Gong, T., Su, W., Yi, J., Fu, Y. \& Liu, L. Practical Carbon-Carbon Bond Formation from Olefins through Nickel-Catalyzed Reductive Olefin Hydrocarbonation. Nat. Commun. 7, 11129 (2016).

29. Lu, X., Xiao, B., Liu, L. \& Fu, Y. Formation of $\mathrm{C}\left(\mathrm{sp}^{3}\right)-\mathrm{C}\left(\mathrm{sp}^{3}\right)$ Bonds through Nickel-Catalyzed Decarboxylative Olefin Hydroalkylation Reactions. Chem. Eur. J. 22, 11161-11164 (2016).

30. Zhou, F., Zhu, J., Zhang, Y. \& Zhu, S. NiH-Catalyzed Reductive Relay Hydroalkylation: A Strategy for the Remote $\mathrm{C}\left(\mathrm{sp}^{3}\right)-\mathrm{H}$ Alkylation of Alkenes. Angew. Chem. Int. Ed. 57, 4058-4062 (2018).

31. Sun, S.-Z., Börjesson, M., Martin-Montero, R. \& Martin, R. Site-Selective Ni-Catalyzed Reductive Coupling of a-Haloboranes with Unactivated Olefins. J. Am. Chem. Soc. 140, 12765-12769 (2018).

32. Bera, S. \& Hu, X. Nickel-Catalyzed Regioselective Hydroalkylation and Hydroarylation of Alkenyl Boronic Esters. Angew. Chem. Int. Ed. 58, 13854-13859 (2019).

33. Sun, S.-Z., Romano, C. \& Martin, R. Site-Selective Catalytic Deaminative Alkylation of Unactivated Olefins. J. Am. Chem. Soc. 141, 16197-16201 (2019).

34. Qian, D. \& Hu, X. Ligand-Controlled Regiodivergent Hydroalkylation of Pyrrolines. Angew. Chem. Int. Ed. 58, 18519-18523 (2019).

35. He, Y., Liu, C., Yu, L. \& Zhu, S. Enantio- and Regioselective NiH-Catalyzed Reductive Hydroarylation of Vinylarenes with Aryl lodides. Angew. Chem. Int. Ed. 59, 21530-21534 (2020). 
36. Cuesta-Galisteo, S., Schörgenhumer, J., Wei, X., Merino, E. \& Nevado, C. Nickel-Catalyzed Asymmetric Synthesis of a-Arylbenzamides. Angew. Chem. Int. Ed. DOI: 10.1002/anie.202011342 (2020).

37. Wang, C., Xi, Y., Huang, W., Qu, J. \& Chen, Y. Org. Lett. DOI: 10.1021/acs.orglett.0c03542 (2020).

38. He, Y., Song, H. \& Zhu, S. NiH-Catalyzed Asymmetric Hydroarylation of N-Acyl Enamines: Practical Access to Chiral Benzylamines. ChemRxiv, doi.org/10.26434/chemrxiv.13084946.v1 (2020).

39. Fu, G. C. Transition-Metal Catalysis of Nucleophilic Substitution Reactions: A Radical Alternative to $\mathrm{S}_{\mathrm{N}} 1$ and $\mathrm{S}_{\mathrm{N}} 2$ Processes. ACS Cent. Sci. 3, 692-700 (2017).

40. Cherney, A. H., Kadunce, N. T. \& Reisman, S. E. Enantioselective and Enantiospecific Transition-MetalCatalyzed Cross-Coupling Reactions of Organometallic Reagents to Construct C-C Bonds. Chem. Rev. $115,9587-9652$ (2015).

41. Wang, Z., Yin, H. \& Fu, G. C. Catalytic Enantioconvergent Coupling of Secondary and Tertiary Electrophiles with Olefins. Nature 563, 379-383 (2018).

42. Zhou, F., Zhang, Y., Xu, X. \& Zhu, S. NiH-Catalyzed Remote Asymmetric Hydroalkylation of Alkenes with Racemic $a$-Bromo Amides. Angew. Chem. Int. Ed. 58, 1754-1758 (2019).

43. He, S.-J., Wang, J.-W., Li, Y., Xu, Z.-Y., Wang, X.-X., Lu, X. \& Fu, Y. Nickel-Catalyzed Enantioconvergent Reductive Hydroalkylation of Olefins with $a$-Heteroatom Phosphorus or Sulfur Alkyl Electrophiles. J. Am. Chem. Soc. 142, 214-221 (2020).

44. Yang, Z.-P. \& Fu, G. C. Convergent Catalytic Asymmetric Synthesis of Esters of Chiral Dialkyl carbinols. J. Am. Chem. Soc. 142, 5870-5875 (2020).

45. Sommer, H., Juliá-Hernández, F., Martin, R. \& Marek, I. Walking Metals for Remote Functionalization. ACS Cent. Sci. 4, 153-165 (2018).

46. Vasseur, A., Bruffaerts, J. \& Marek, I. Remote Functionalization through Alkene Isomerization. Nat. Chem. 8, 209-219 (2016).

47. Shi, L., Xing, L.-L., Hu, W.-B. \& Shu, W. Regio- and Enantioselective Ni-Catalyzed Formal Hydroalkylation, Hydrobenzylation, and Hydropropargylation of Acrylamides to $\alpha$-Tertiary Amides. Angew. Chem. Int. Ed. 59, DOI: 10.1002/anie.202011339 (2020).

48. Bera, S., Mao, R. \& Hu, X. Enantioselective C(sp $\left.{ }^{3}\right)-C\left(\mathrm{sp}^{3}\right)$ Cross-Coupling of Non-Activated Alkyl Electrophiles via Nickel Hydride Catalysis. ChemRxiv doi.org/10.26434/chemrxiv.12040398.v1 (2020).

49. Wang, J.-W., Li, Y., Nie, Chang, Z., Yu, Z.-A., Zhao, Y.-F., Lu, X. \& Fu, Y. Catalytic Asymmetric Reductive Alkylation of Enamines to Chiral Aliphatic Amines. ChemRxiv, doi.org/10.26434/chemrxiv.13102307.v1 (2020).

50. Qian, D., Bera, S. \& Hu, X. Chiral Alkyl Amine Synthesis via Catalytic Enantioselective Hydroalkylation of Enamides. ChemRxiv, doi.org/10.26434/chemrxiv.13096121.v1 (2020).

51. Wang, S., Zhang, T.-Y., Zhang, J.-X., Meng, H., Chen, B.-H. \& Shu, W. Enantioselective Access to Dialkyl Amines and Alcohols via Ni-Catalyzed Reductive Hydroalkylations. ChemRxiv, doi.org/10.26434/chemrxiv.13284416.v1 (2020). 
52. For more details on the condition optimization, please see Supporting Information.

53. Matteson, D. S., Ray, R., Rocks, R. R. \& Tsai, D. J. S. Directed Chiral Synthesis by Way of a-Chloro Boronic Esters. Organometallics 2, 1536-1543 (1983).

54. Wei, X., Shu, W., García-Domínguez, A., Merino, E. \& Nevado, C. Asymmetric Ni-Catalyzed Radical Relayed Reductive Coupling. J. Am. Chem. Soc. 142, 13515-13522 (2020).

55. Kleman, P., Gonzlez-Liste, P. J., Garca-Garrido, S. E., Cadierno, V. \& Pizzano, Highly Enantioselective Hydrogenation of 1-Alkylvinyl Benzoates: A Simple, Nonenzymatic Access to Chiral 2-Alkanols. Chem. Eur. J. 19, 16209-16212 (2013).

\section{Supplementary Information}

Table 1, Equation 1, and Scheme 1 are available in the Supplementary Files

\section{Figures}




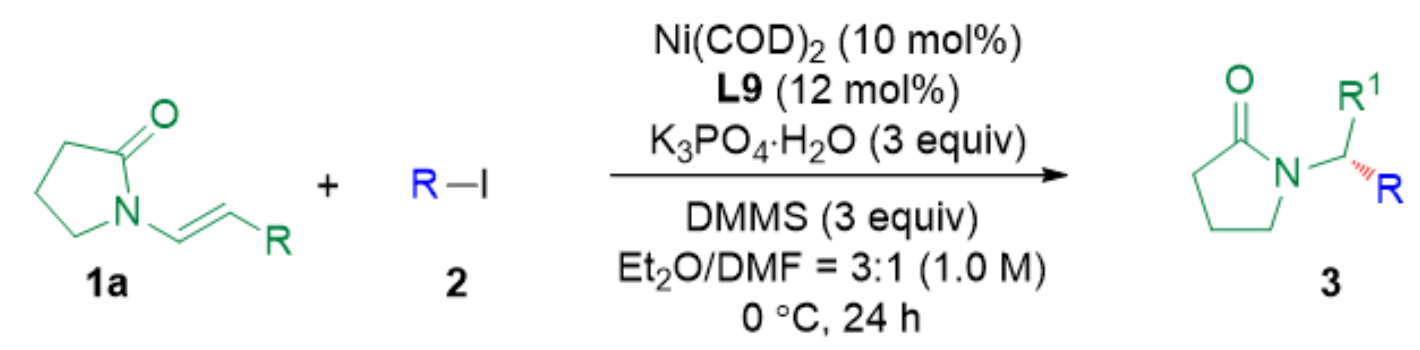

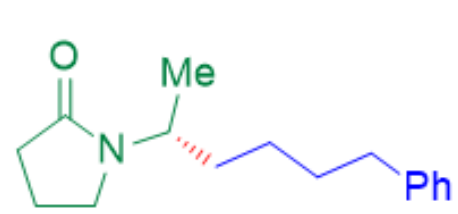

3b, $93 \%, 92 \%$ ee<smiles>C[C@@H](CCc1ccccc1)N1CCCC1=O</smiles>

3c, $87 \%, 89 \%$ ee

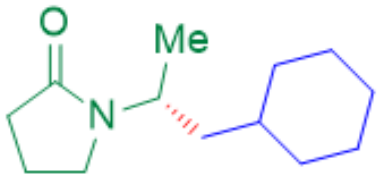

$3 d, 58 \%, 89 \%$ ee<smiles>CC(C)N1C=CCC1=O</smiles>

$3 e, 92 \%, 91 \%$ ee<smiles>CC(=O)O[Na]</smiles>

3f, $94 \%, 91 \%$ ee<smiles>CCOC(=O)CCC[C@H](C)N1CCCC1=O</smiles>

$3 \mathbf{i}, 83 \%, 89 \%$ ee<smiles>C[C@H](CCCCCO[Si](c1ccccc1)(c1ccccc1)C(C)(C)C)N1CCCC1=O</smiles>

3I, $85 \%, 74 \%$ ee<smiles>C[C@@H](CCCc1cccs1)N1CCCC1=O</smiles>

$3 g, 64 \%, 91 \%$ ee<smiles>COCCCC[C@H](C)N1CCCC1=O</smiles>

3j, $65 \%, 92 \%$ ee<smiles>C[C@H](CCc1cccc(Cl)c1)N1CCCC1=O</smiles>

$3 \mathrm{~m}, 95 \%$, 88\% ee<smiles>C[C@H](CCCN1C(=O)c2ccccc2C1=O)N1CCCC1=O</smiles>

$3 \mathrm{~h}, 83 \%, 91 \%$ ee<smiles>C[C@H](CCOc1ccccc1)N1CCCC1=O</smiles>

$3 k, 56 \%, 89 \%$ ee<smiles>CC[C@H](CCCn1c2ccccc2c2ccccc21)N1CCCC1=O</smiles>

$3 n, 40 \%, 93 \%$ ee (from $(E)$-acyl enamine)

Figure 1

Scope of the alkyl iodides for tertiary acyl enamines. 


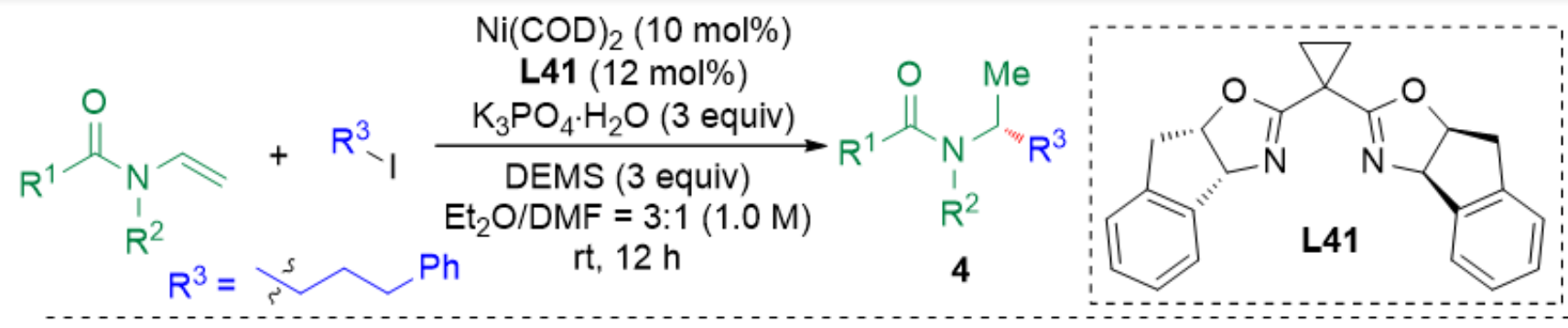<smiles>[R]C(C)NC(=O)c1ccc(C(=O)NC([R])C)cc1</smiles>

$4 a, 84 \%, 93 \%$ ee<smiles>[R]C(C)NC(=O)c1cc(C)cc(C)c1</smiles>

4 e, $79 \%, 95 \%$ ee<smiles>[R]C(C)NC(=O)c1ccc(C(=O)OC)cc1</smiles>

$4 i, 74 \%, 96 \%$ ee<smiles>[R]C(C)NC(=O)c1cccc2ccccc12</smiles>

4I, $68 \%, 93 \%$ ee<smiles>[R]C(C)NC(=O)c1ccc(Cl)nc1</smiles>

$40,49 \%, 89 \%$ ee<smiles>[R]C(C)NC(=O)C1CC1</smiles>

4s, $88 \%, 96 \%$ ee 4b, $82 \%, 93 \%$ ee<smiles>[R]C(C)NC(=O)c1ccc(OC)cc1</smiles>

4c, $90 \%, 94 \%$ ee<smiles>[R]C(C)NC(=O)c1cccc(C)c1</smiles>

4d, $87 \%, 94 \%$ ee<smiles>[R]C(C)NC(=O)c1ccccc1C</smiles>

4f, $68 \%, 90 \%$ ee<smiles>[R]C(C)NC(=O)c1ccc(C(F)(F)F)cc1</smiles>

4g, $88 \%, 95 \%$ ee $\mathrm{Me}$<smiles>[R]C(C)NC(=O)c1ccccc1F</smiles>

4j, $82 \%, 93 \%$ ee<smiles>[R]C(C)NC(=O)c1ccc(C#N)cc1</smiles>

4h, $89 \%, 94 \%$ ee<smiles>[R]C(C)NC(=O)c1ccc2ccccc2c1</smiles>

4k, $88 \%, 95 \%$ ee<smiles>[R]C(C)NC(=O)c1cccs1</smiles>

$4 \mathrm{~m}, 81 \%, 95 \%$ ee

4n, $68 \%, 95 \%$ ee<smiles>[R]C(C)NC(=O)C(C)C</smiles>

4q, $51 \%, 93 \%$ ee<smiles>[R]C(C)NC(=O)C(C)(C)C</smiles>

$4 u, 84 \%, 92 \%$ ee
$4 r, 68 \%, 90 \% e^{a}$<smiles>[R]C(C)NC(=O)C(C)C</smiles><smiles>[R]C(C)N(C)C(C)=O</smiles>

$4 \mathbf{v}, 79 \%, 80 \%$ ee ${ }^{b}$

Figure 2

Scope for the acyl enamines. a DMMS was used instead of DEMS. b L4 was used as the ligand. 


$$
\begin{aligned}
& \mathrm{Ni}(\mathrm{COD})_{2}(10 \mathrm{~mol} \%)
\end{aligned}
$$

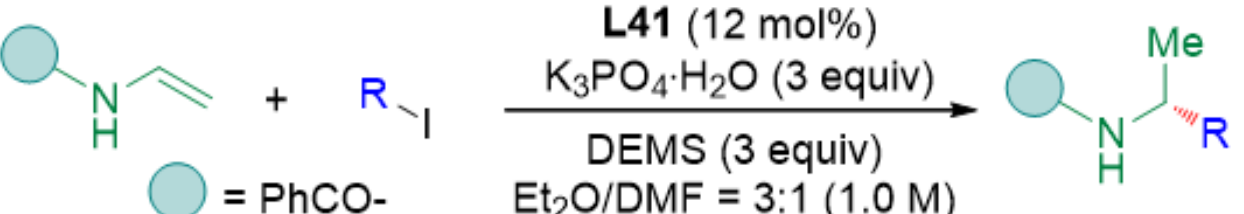

$$
\begin{aligned}
& \text { rt, } 12 \mathrm{~h}
\end{aligned}
$$<smiles>C[C@H](CCc1ccc2c(c1)CCO2)Nc1ccccc1</smiles>

5a, $84 \%, 96 \%$ ee<smiles>CCCC(C)NC=O</smiles>

5d, $75 \%, 93 \%$ ee<smiles>CCOC(=O)CCC[C@H](C)NC=O</smiles>

5h, $72 \%, 94 \%$ ee

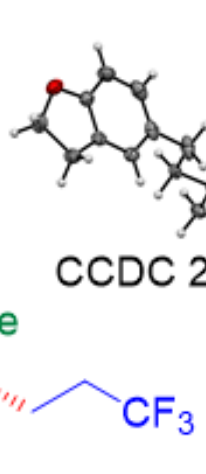

5 e, $80 \%, 98 \%$ ee<smiles></smiles>

5f, $65 \%, 92 \%$ ee<smiles>CCCC[C@H](C)Nc1ccccc1</smiles>

5c, $63 \%, 93 \%$ ee<smiles>[M]C(CCC(=O)OC1CC(C)CCC1C(C)C)NC1CCCC1</smiles>

$5 i, 66 \%, 98 \%$ ee<smiles>C[C@H](Nc1ccccc1)C1CCNCC1</smiles>
Boc<smiles>CC(CC=[Se]O)NC(=O)O</smiles>

$5 g, 62 \%, 94 \%$ ee<smiles>CC(NC=O)C1COC1</smiles><smiles>O=C(O)Nc1ccccc1</smiles><smiles>CNC(C)CCC(=O)OC1CC2CCC1(C)C2(C)C</smiles>

5I, $87 \%, 97: 3 d r$

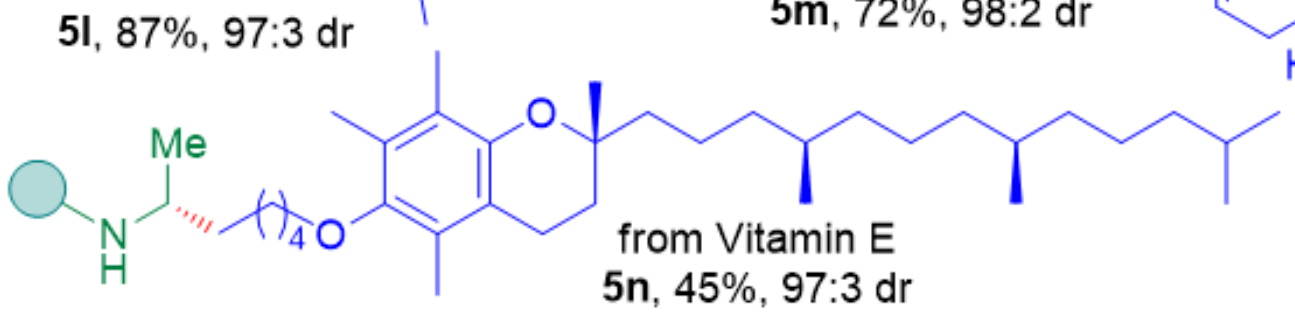

from (+)-Borneol $5 k, 62 \%, 98: 2 d r$<smiles>CCCCC(C)NC=O</smiles>
from Cholesterol $5 \mathrm{~m}, 72 \%, 98: 2 \mathrm{dr}$

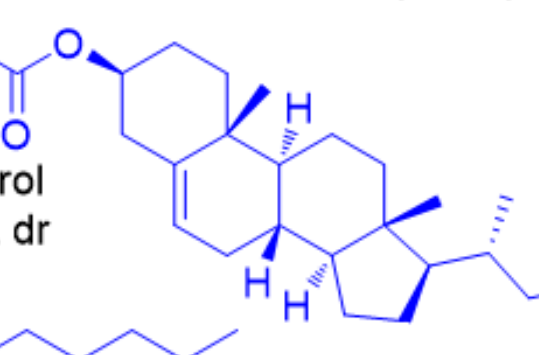

Figure 3

Scope for the alkyl iodides for secondary acyl enamines. 


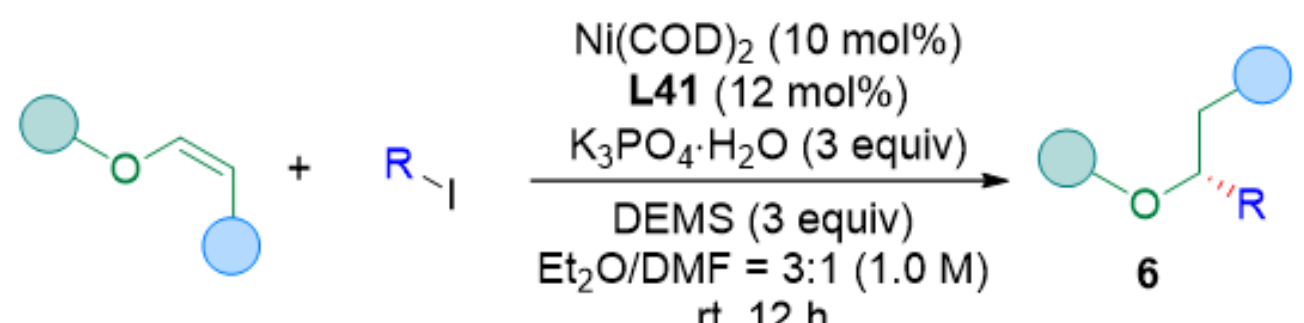

$\mathrm{rt}, 12 \mathrm{~h}$<smiles>C[C@H](CCCc1ccccc1)OC(=O)c1ccccc1</smiles>

$6 a, 73 \%, 91 \%$ ee<smiles>CCOC(=O)CCC[C@H](C)OC(=O)c1ccccc1</smiles>

6d, $68 \%, 93 \%$ ee<smiles>C[C@H](CCCN1C(=O)c2ccccc2C1=O)OC(=O)c1ccccc1</smiles>

$6 \mathrm{~g}, 51 \%, 95 \%$ ee<smiles>C[C@H](OC(=O)c1ccccc1)C1COC1</smiles>

6j, 37\%, 97\% ee $b$<smiles>C[C@H](CCCc1ccccc1)OC(=O)c1ccc2ccccc2c1</smiles>

6b, $67 \%, 92 \%$ ee<smiles>COCCCC[C@H](C)OC(=O)c1ccccc1</smiles>

$6 e, 65 \%, 93 \%$ ee<smiles>CCCCCC[C@H](C)OC(=O)c1ccccc1</smiles>

$6 h, 77 \%, 90 \%$ ee<smiles>O=C(OC(CCCc1ccccc1)CCCc1ccccc1)c1ccccc1</smiles>

6k, 40\%, 97\% ee (from (Z)-enol ester)

Figure 4

Scope for the reductive hydroalkylation of enol esters. a 5 equiv of RI was used. b 3 equiv of RI was used. 


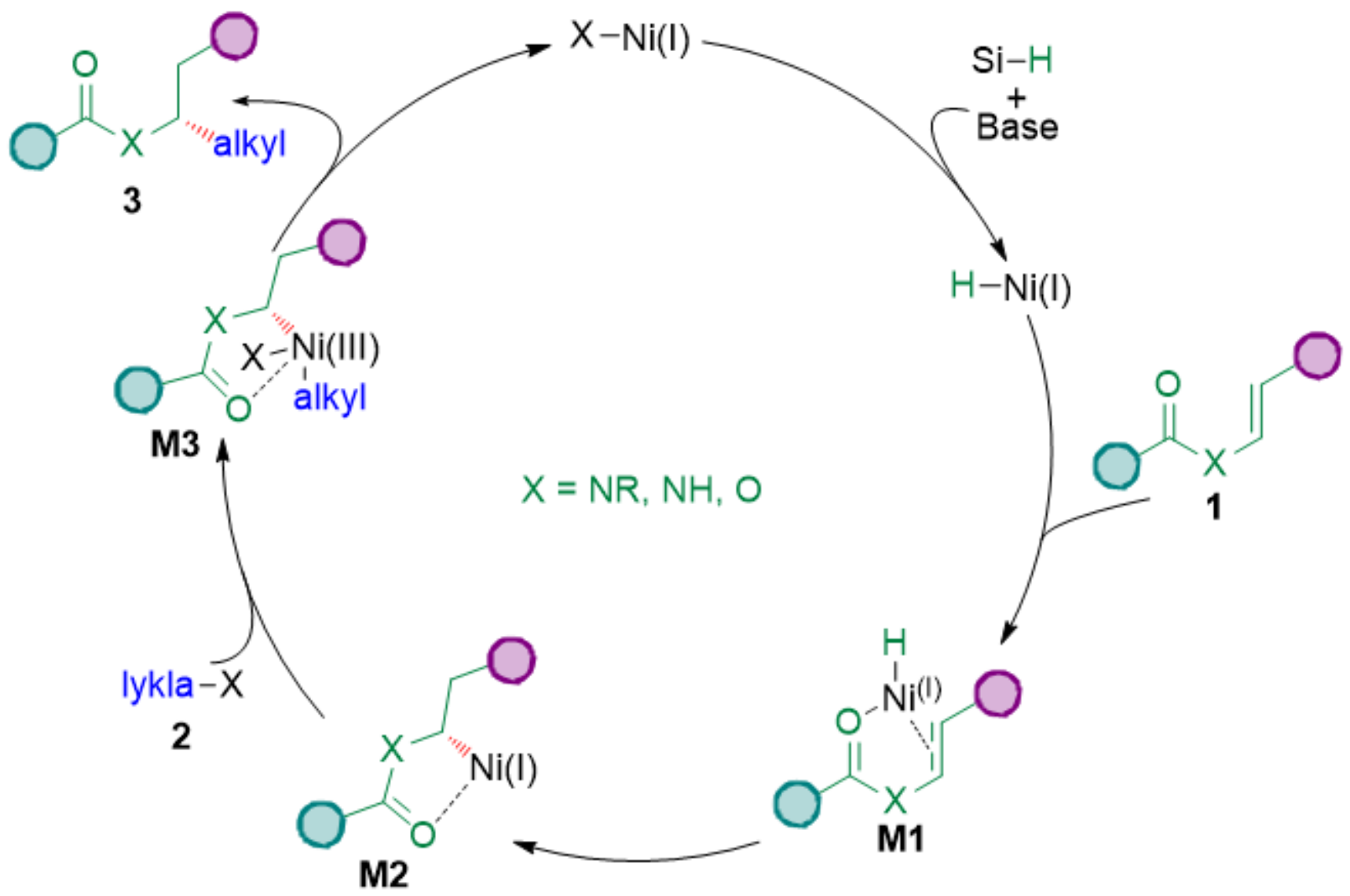

Figure 5

Proposed mechanism for the reaction. Ligand is omitted for clarity.

\section{Supplementary Files}

This is a list of supplementary files associated with this preprint. Click to download.

- Scheme1.png

- Equation1.png

- Table1.png

- SupportingInformation.pdf 